\title{
Detection of Helicobacter pylori in gastric biopsy and resection specimens
}

\author{
M Ashton-Key, T C Diss, P G Isaacson
}

\begin{abstract}
Aims-To compare the sensitivity of detecting Helicobacter pylori in gastric biopsy and resection specimens using tinctorial and silver impregnation stains, immunohistochemistry and the polymerase chain reaction (PCR).

Methods-Formalin fixed, paraffin wax embedded tissue from 33 gastric biopsy specimens (26 showing chronic gastritis and seven showing low grade mucosa associated lymphoid tissue (MALT) lymphoma) together with blocks of uninvolved mucosa from gastrectomy specimens for MALT lymphoma (five cases) were studied. Consecutive sections were stained using haematoxylin and eosin, Giemsa, the Warthin-Starry silver stain, and a polyclonal antibody directed against $H$ pylori using an immunoperoxidase technique following heat induced antigen retrieval. PCR analysis of DNA extracted from a further section was carried out using primers which amplified a 411 base pair fragment of the urease $A$ gene.
\end{abstract}

Results-H pylori was detected in 14 (37\%) sections stained with haematoxylin and eosin, 21 (55\%) with Giemsa, 23 (61\%) with Warthin-Starry, and $25(66 \%)$ stained with the antibody. Seventeen ( $45 \%)$ cases were positive on PCR. Immunohistochemistry was positive in all cases in which $H$ pylori was detected by other methods.

Conclusion-Immunohistochemistry using an immunoperoxidase technique following heat induced antigen retrieval for detecting $H$ pylori in gastric biopsy and resection specimens is highly sensitive and easy to use.

(f Clin Pathol 1996;49:107-111)

Keywords: Helicobacter pylori, detection, immunohistochemistry, PCR.

Department of Histopathology, University College London Medical

School, London

M Ashton-Key

T C Diss

P G Isaacson

Correspondence to: Dr M Ashton-Key, Department of Histopathology, University College London Medical School, Rockefeller Building University Street, London WC1E 6JJ.

Accepted for publication 18 October 1995
Helicobacter pylori infection is associated with gastritis and has also been implicated in the pathogenesis of gastric carcinoma and lymphoma. ${ }^{1-5}$ There are a number of methods for detecting $H$ pylori, including the breath test, the urease test and culture, but histological detection in a gastric biopsy is the commonest and among the most sensitive. ${ }^{6-11}$ Accurate detection of the organism is essential for correct patient management and it is particularly important to confirm eradication of bacteria following treatment. The spiral shaped bacteria can be seen in routine haematoxylin and eosin sections but are more easily detected with spe- cial stains such as Giemsa or the WarthinStarry silver stain. None of these stains is specific for the organism and all may be difficult to interpret because of non-specific staining of mucus, debris and water bath contaminants. Moreover, the Warthin-Starry stain, which is considered to be the most sensitive, is technically demanding and frequently not reproducible. Optimal interpretation of these stains requires careful examination of the sections at high magnification.

More recently, immunohistochemistry, in situ hybridisation and the polymerase chain reaction (PCR) have been proposed as alternative specific detection methods, ${ }^{912-18}$ but these techniques have not been compared with routine tinctorial stains. In this study we have compared traditional detection methods, using haematoxylin and eosin, Giemsa and Warthin-Starry stained sections with immunohistochemistry using a commercially available anti- $H$ pylori antibody and PCR on DNA extracted from paraffin wax sections.

\section{Methods}

Formalin fixed, paraffin wax embedded tissue blocks from gastric biopsy specimens showing chronic gastritis (26 cases) and low grade B cell mucosa associated lymphoid tissue (MALT) lymphoma (seven cases) together with blocks of uninvolved mucosa from gastrectomy specimens for MALT lymphoma (five cases, three high grade and two low grade), were retrieved from the files of the Histopathology Department of UCL Medical School, London, and the histology reviewed. Chronic gastritis was defined as the presence of an infiltrate of plasma cells and lymphocytes, with or without active inflammation and lymphoid aggregates. All sections were stained with haematoxylin and eosin, Giemsa and the Warthin-Starry silver impregnation method.

\section{IMMUNOHISTOCHEMISTRY}

Paraffin wax sections were heated in sodium citrate buffer ( $\mathrm{pH} 6.0,0.01 \mathrm{M})$ in a pressure cooker at $130^{\circ} \mathrm{C}$ for two minutes prior to immunostaining with anti- $H$ pylori antibody (Dako, High Wycombe, UK) at a 1 in 1000 dilution using a standard Streptavidin-biotin complex method. ${ }^{1920}$

\section{MICROSCOPIC EVALUATION}

Sections were evaluated for the features of chronic gastritis, which included the presence of an infiltrate of plasma cells and lymphocytes 
Detection of $\mathrm{H}$ pylori-summary of the results obtained with the different detection methods used

\begin{tabular}{|c|c|c|c|c|c|}
\hline \multirow[b]{2}{*}{ Specimen type } & \multicolumn{5}{|c|}{ Detection method [number of positive cases (\%)] } \\
\hline & $\begin{array}{l}\text { Haematoxylin } \\
\text { and eosin }\end{array}$ & Giemsa & Warthin-Starry & Immunoperoxidase & $P C R$ \\
\hline $\begin{array}{l}\text { Gastritis }(n=26) \\
\text { MALT lymphoma biopsy }(n=7) \\
\text { Gastrectomy }(n=5)\end{array}$ & $\begin{aligned} 10(38) \\
4(57) \\
0(0)\end{aligned}$ & $\begin{aligned} 13 & (50) \\
7 & (100) \\
1 & (20)\end{aligned}$ & $\begin{array}{r}14(54) \\
6(86) \\
3(60)\end{array}$ & $\begin{aligned} 15 & (58) \\
7 & (100) \\
3 & (60)\end{aligned}$ & $\begin{aligned} & 12(46) \\
& 5(71) \\
& 0(0)\end{aligned}$ \\
\hline Total $(n=38)$ & $14(37)$ & $21(55)$ & $23(61)$ & $25(66)$ & $17(45)$ \\
\hline
\end{tabular}

in the lamina propria with or without acute inflammation and lymphoid aggregates, and/ or the presence of low grade B cell MALT lymphoma. The haematoxylin and eosin, Giemsa, Warthin-Starry, and immunoperoxidase stained sections were carefully examined for the presence of $\mathrm{H}$ pylori-like organisms using a $\times 60$ objective with $\times 10$ eyepieces. Each stain was assessed on a different day without referring to the results of the other stains.

\section{POLYMERASE CHAIN REACTION}

DNA was extracted from serial sections of the paraffin wax embedded material as described previously. ${ }^{21}$ PCR amplification of a 411 base pair fragment from the urease A gene of $H$ pylori was carried out as described by Clayton et al. $^{22}$

PCR was carried out in a reaction mix containing $10 \mathrm{mM}$ Tris (pH 9), $50 \mathrm{mM} \mathrm{KCl}$, $200 \mathrm{mM}$ of each dNTP, $250 \mathrm{ng}$ of each primer (HP1: 5'-GCCAATGGTAAATTAGTT-3'; HP2: 5'-CTCCTTAATTGTTTTTAC-3'), $0 \cdot 1 \%$ Triton X-100, $5 \mu 1$ DNA extract, and 0.5 units Taq polymerase (Promega, Southampton, UK; added at $50^{\circ} \mathrm{C}$ following initial denaturation) in a total volume of $50 \mu \mathrm{l}$. The PCR conditions were as follows: 40 cycles of $93^{\circ} \mathrm{C}$ for 45 seconds, $50^{\circ} \mathrm{C}$ for 40 seconds and $72^{\circ} \mathrm{C}$ for one minute 50 seconds, followed by 10 minutes at $72^{\circ} \mathrm{C}$.

In each experiment a positive control $H$ pylori extract and a negative control (no DNA) were run in parallel with the test cases. Products were run on $2 \%$ agarose gels, stained with ethidium bromide and viewed under ultraviolet light. Cases yielding a 411 base pair product were scored as positive.

\section{Results}

The table summarises the results. The presence of chronic gastritis was confirmed in the 26 gastric biopsy specimens and in the uninvolved mucosa from the five MALT lymphoma gastrectomy specimens. A diagnosis of low grade B cell MALT lymphoma was confirmed in seven gastric biopsy specimens.

$H$ pylori was identified in 14 sections stained with haematoxylin and eosin (10/26 biopsy specimens with chronic gastritis, four/seven biopsy specimens with MALT lymphoma, zero/ five sections from gastrectomy specimens). $H$ pylori could be identified with greater frequency in sections stained with Giemsa; 21 were positive (13/26 biopsy specimens with chronic gastritis, seven/seven biopsy specimens with MALT lymphoma and one/five gastrectomy sections). $H$ pylori could be detected at a still greater frequency in Warthin-Starry stained sections; 23 were positive ( $14 / 26$ biopsy specimens with chronic gastritis, six/seven with MALT lymphoma and three/five gastrectomy sections). On staining with immunoperoxidase, 25 cases were positive (15/26 biopsy specimens with chronic gastritis, seven/seven with MALT lymphoma and three/five gastrectomy sections). In all cases the bacteria were more prominent and easier to detect in the immunostained sections than in sections stained tinctorially. With the tinctorial and silver stains a high power or even an oil

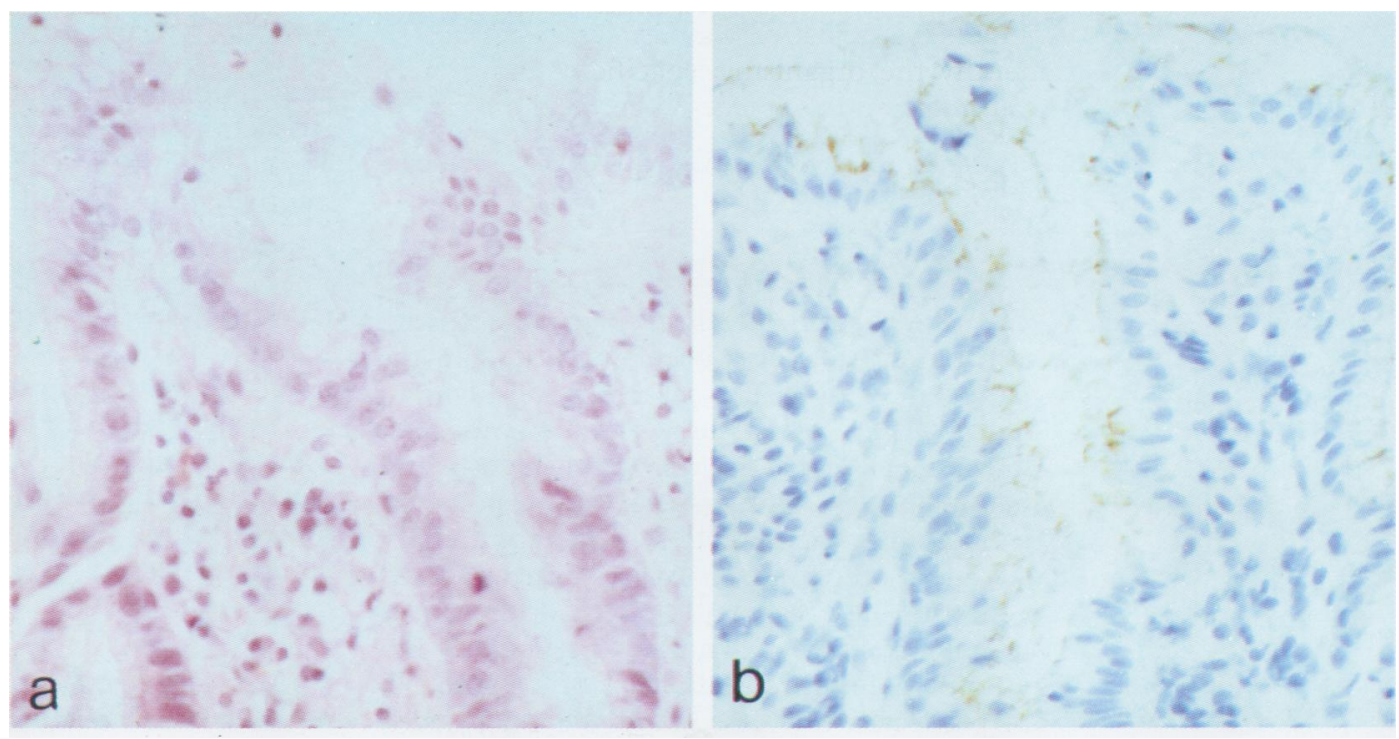

Figure 1 (a) Gastric biopsy specimen showing chronic gastritis. (b) $\mathrm{H}$ pylori can be seen in the immunostained sections. 

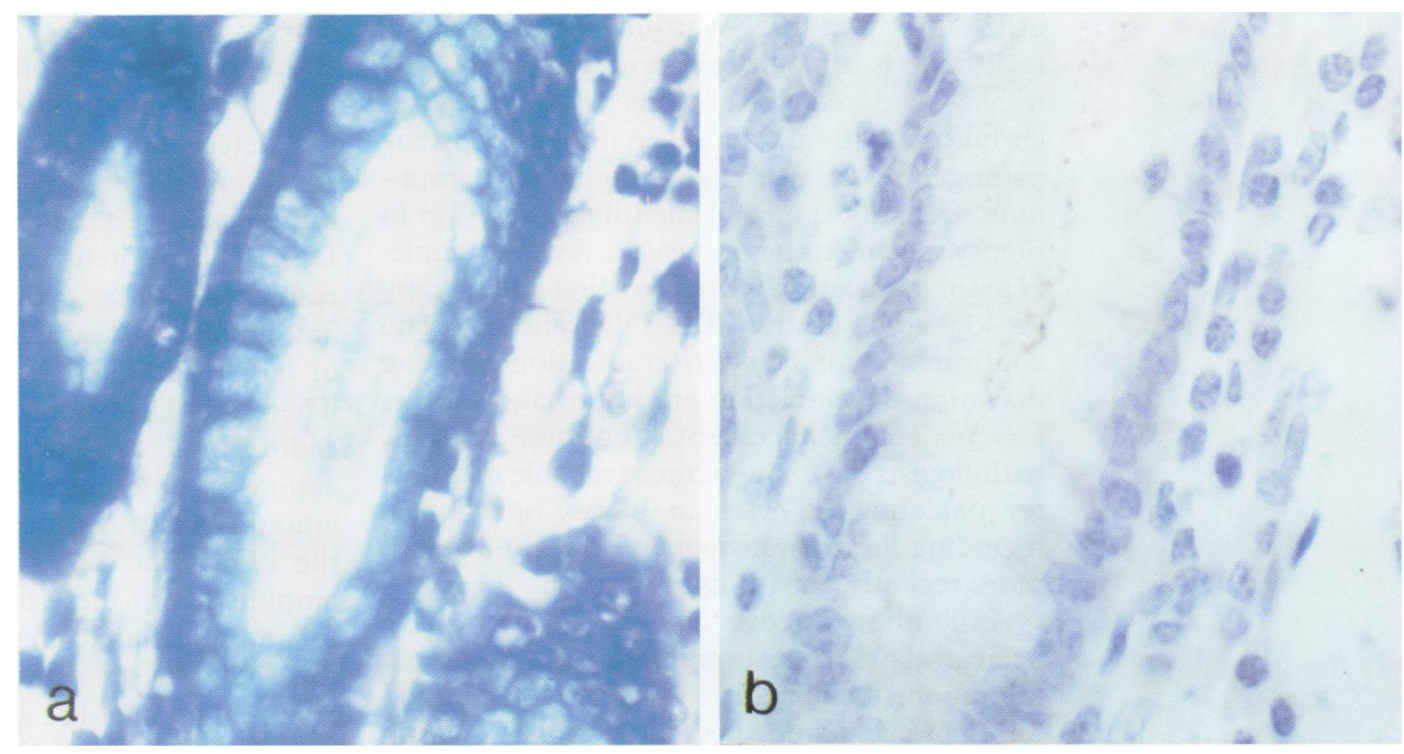

Figure 2 Gastrectomy for MALT lymphoma. H pylori hidden within mucus in Giemsa stained sections (a) are obvious in the immunoperoxidase stained sections (b).
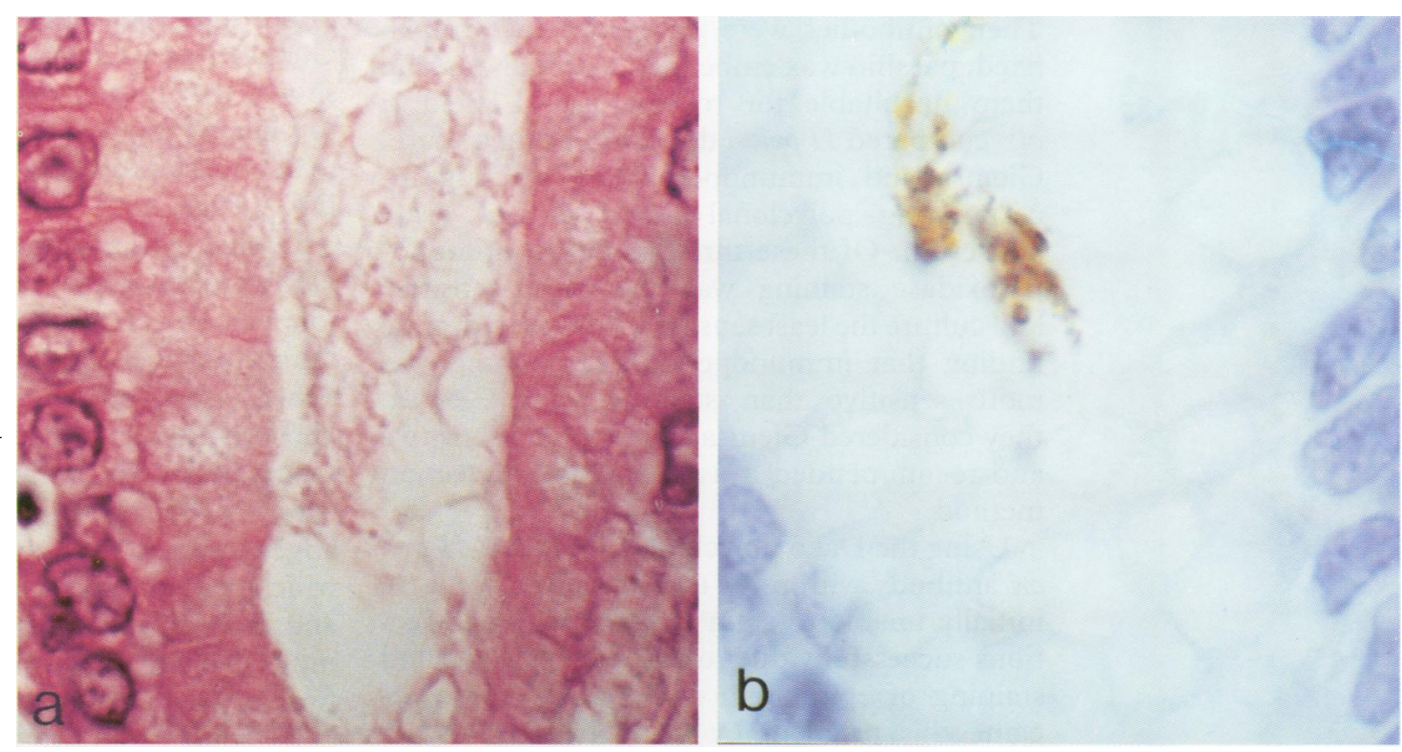

Figure 3 The coccoid form of $\mathrm{H}$ pylori in haematoxylin and eosin stained sections (a) can be identified with certainty using immunohistochemistry (b).

immersion objective was always necessary to identify the organisms; specific staining of $H$ pylori in immunostained preparations could easily be seen using the $\times 10$ or $\times 20$ objective, even when very few organisms were present (fig 1).

Several patterns of distribution of $H$ pylori were identified. Organisms attached to the brush border of the gastric foveolar epithelial cells or within the superficial mucus were most easily seen. In some cases, however, the bacteria were masked in haematoxylin and eosin and Giemsa stained sections by inspissated mucus or by being positioned flat, closely apposed to the epithelial surface. These organisms were more easily seen with the Warthin-Starry stain but were strikingly obvious in immunostained preparations. Some difficulty was encountered in differentiating $\mathrm{H}$ pylori from debris in Giemsa and Warthin-Starry stained sections where water bath contaminants also posed a problem in occasional cases. Similarly, coccoid or- ganisms, which were particularly seen in sections from resection specimens, caused some uncertainty. The specificity of immunostaining obviated all of these difficulties (figs 2 and 3).

When DNA extracted from the sections was amplified using PCR, $H$ pylori were identified in 17 cases ( $12 / 26$ biopsy specimens with chronic gastritis, five/seven MALT lymphomas and zero/five gastrectomy sections).

\section{Discussion}

Previous studies have emphasised that staining with haematoxylin and eosin is not adequate for detecting $H$ pylori and that staining with Giemsa or the use of the Warthin-Starry or related silver impregnation techniques are the methods of choice. ${ }^{1011}$ However, the latter techniques are not specific for $H$ pylori and, as confirmed in our study, both generate false positive results because of bacterial contaminants or debris. Moreover, many laborat- 
ories find that the Warthin-Starry staining technique is difficult to reproduce reliably. As it has been recognised that $H$ pylori causes chronic gastritis and has been implicated in the pathogenesis of gastric carcinoma and lymphoma, the importance of identifying $H$ pylori in biopsy specimens has increased. As an example, $H$ pylori eradication is used as a first line therapy for low grade gastric MALT lymphoma. ${ }^{3}$ The confirmation of $H$ pylori eradication and the detection of reinfection are important for correct patient management. For these reasons, pathologists have sought more reliable methods for detecting $H$ pylori in biopsy specimens, including immunohistochemistry, PCR and, more recently, in situ hybridisation.

Antibodies reactive against $H$ pylori have been available for several years, ${ }^{12-14}$ although immunohistochemistry as a detection method for $H$ pylori has not become popular. Negrini et $a l^{12}$ raised several monoclonal antibodies against $H$ pylori and were able to show specific staining of the organism in gastric brushings and frozen sections of gastric biopsy specimens. Their antibodies were unreactive in formalin fixed, paraffin wax embedded material, making them unsuitable for routine use. Loffeld et $a l^{13}$ compared $H$ pylori detection using culture, Giemsa and immunoperoxidase staining incorporating polyclonal rabbit anti- $H$ pylori antiserum. Of these three methods, immunoperoxidase staining was the most sensitive and culture the least sensitive. However, despite finding that immunoperoxidase staining was more sensitive than staining with Giemsa, they considered Giemsa staining very sensitive and recommended it as the routine detection method.

Using the Dako polyclonal rabbit anti- $H$ pylori antibody with prior trypsinisation, we were initially unable to stain $H$ pylori in tissue sections successfully due to excessive background staining of epithelium and mucus. We overcame this problem by using heating, rather than trypsin, as the antigen retrieval method. This enabled us to use the antibody at a dilution of 1 in 1000 with a proportional reduction in background staining. Our laboratory has found that this method is easy to use, less demanding than Warthin-Starry staining, and that it produces reliable results which are easy to interpret. Low numbers or even single organisms, often difficult to detect using traditional stains, are easily identified in immunostained sections. A further advantage of immunoperoxidase staining is the ability to identify the coccoid form of $H$ pylori, which cannot be identified confidently using traditional stains and which cannot be cultured.

Molecular techniques including PCR and in situ hybridisation have both been suggested recently as specific methods for the detection of $H$ pylori. ${ }^{915-18}$ PCR has become particularly popular and has been shown to be a very specific detection method, although sensitivity does vary depending on the primers used, the source of DNA and number of bacteria present. In this study PCR was more sensitive than staining with haematoxylin and eosin but less sensitive than the other methods investigated.
There are several possible reasons for this. Although serial sections were used for the PCR only a small amount of DNA is sampled. This will detect the organisms if they are numerous but if only scanty bacteria are present the DNA sample analysed may not include any bacterial DNA. This potential source of false negative results could be reduced by increasing the amount of DNA sampled either by repeat PCRs or larger aliquots of extract in each reaction. There are disadvantages to both of these procedures; increasing the number of PCR reactions is time consuming and increasing the amount of extract in each reaction may inhibit the PCR. The 411 base pair DNA fragment amplified with these primers is relatively large for amplification from paraffin wax sections and this may have resulted in some false negative results. This could be avoided by using different primers which amplify a smaller fragment. Using fresh tissue and primers which amplified a 210 base pair fragment, Fabre et al ${ }^{17}$ were able to detect $H$ pylori infection in the same proportion of biopsy specimens as using Giemsa stained sections. In this study we have shown that immunohistochemistry is superior to Giemsa staining and therefore is also likely to be superior to PCR using primers to a smaller DNA fragment.

In situ hybridisation, using both RNA and DNA probes, is a sensitive and specific method for detecting $H$ pylori in tissue sections. ${ }^{1516}$ Like immunohistochemistry, in situ hybridisation shows strong specific staining of the bacteria and permits direct comparison with histology. Compared with immunohistochemistry, however, in situ hybridisation has several disadvantages; it is a more complex technique which requires specially trained technical staff and few routine laboratories have access to molecular facilities whereas most already perform immunohistochemistry.

In conclusion, we have shown that using a heat mediated antigen retrieval technique, immunohistochemistry is a highly sensitive method for identifying $H$ pylori in gastric biopsy specimens. It is more sensitive than traditional stains and considerably easier to interpret. We recommend immunohistochemistry as the method of choice for the identification of $H$ pylori in gastric biopsy specimens. However, in most histopathology departments the number of gastric biopsy specimens is large and the resources for immunohistochemistry are limited. Although it would be ideal, it is clearly not practical to perform $H$ pylori immunohistochemistry on every gastric biopsy specimen. For routine use immunohistochemistry could be reserved for the following three groups: (1) biopsy specimens which show chronic gastritis and are negative for $H$ pylori using haematoxylin and eosin and Giemsa stains; (2) post-treatment biopsy specimens for MALT lymphoma, to ensure eradication therapy has been successful; and (3) biopsy specimens in which coccoid forms or other organisms not definitely identifiable as $H$ pylori using routine stains are present. 
1 Marshall BJ, Warren JR. Unidentified curved bacilli in the stomach of patients with gastritis and peptic ulceration stomach of patients with

2 Goodwin CS, Armstrong JA, Marshall BJ. Campylobacter pyloridis, gastritis and peptic ulceration. $f$ Clin Pathol 1986;39:353-65.

3 Wotherspoon AC, Doglioni C, Diss TC, Pan L, Maschini A, de Boni M, et al. Regression of primary low-grade Bcell gastric lymphoma of mucosa-associated lymphoid tissue after eradication of Helicobacter pylori. Lancet 1993 342:575-7.

4 Wotherspoon A, Ortiz-Hidalgo C, Falzon MR, Isaacson PG. Helicobacter pylori-associated gastritis and primary B-cell gastric lymphoma. Lancet 1991;338:1175-6.

5 Parsonnet J, Friedman GD, Vandersteen DP, Chang Y, Vogelman $\mathrm{JH}$, Orentreich $\mathrm{N}$, et al. Helicobacter pylor infection and the risk of gastric carcinoma. $N \mathrm{Engl} \mathcal{F} \mathrm{Med}$ 1991;325:1127-31.

6 Graham DY, Klein PD, Evans DJ jr, Evans DG, Alpert LC, Opekun AR, et al. Campylobacter pylori detected noninvasively by the ${ }^{13} \mathrm{C}$-urea breath test. Lancet $1987 ; \mathbf{i}$ noninvasive

7 McNulty CAM, Dent JC, Uff JS, Gear MW, Wilkinson SP. Detection of Campylobacter by the biopsy urease test: an assessment in 1445 patients. Gut 1989;30:1058-62.

8 Goodwin CS, Blincow ED, Warren JR, Waters TE Sanderson CR, Easton L. Evaluation of cultura techniques for isolating Campylobacter pyloridis from endoscopic biopsies of gastric mucosa. $f$ Clin Pathol 1985; 38:1127-31.

9 Weiss J, Mecca J, da Siwa E, Gassner D. A comparison of PCR and other techniques for detection of Helicobacter pylori infection in dyspeptic patients. $f$ Clin Microbio 1994;32:1663-8

10 Kolts BE, Joseph B, Achem SR, Bianchi T, Monteiro C. Helicobacter pylori detection: A quality and cost analysis. Am $\mathcal{f}$ Gastroenterol 1993;88:650-5.

11 Miller NM, Sathar MA, Naran AD, Van den Ende, Simjee $\mathrm{AE}$, Manion G. Evaluation of various techniques to diagnose Helicobacter pylori in patients with upper gastronose Helicobacter pylori in patients with upper gastro-
intestinal tract symptoms. $S$ Afr Med $f 1991 ; 80: 575-8$.

12 Negrini R, Lisato L, Cavazzini L, Manini P, Gullini S, Basso O. Monoclonal antibodies for specific immunoperoxidase detection of Campylobacter pylori. Gastroenterology 1989; 96:414-20.

13 Loffeld RJ, Stobberingh E, Flendrig JA, Arends JW. Helicobacter pylori in gastric biopsy specimens. Comparison of culture, modified giemsa stain and immunoof culture, modifed giemsa stain and immunohistoch $69-73$.

14 Cartun RW, Kryzmowski GA, Pedersen CA, Morin SG Van Kruiningen HJ, Berman MM. Immunocytochemical identification of Helicobacter pylori in formalin-fixed gastric biopsies. Mod Pathol 1991;4:498-502.

15 Van den Berg FM, Zijlmans H, Langenberg W, Rauws E, Schipper M. Detection of Campylobacter in stomach tissue by DNA in-situ hybridisation. $\mathcal{F}$ Clin Pathol 1989; 42:995-1000.

16 Bashir MS, Lewis MS, Quirke P, Lee A, Dixon MF. In-situ hybridisation for the identification of Helicobacter pylori in paraffin wax embedded tissue. $\mathcal{F}$ Clin Pathol 1994;47: in para $862-4$.

17 Fabre R, Sobhani I, Laurent-Puig P, Hedef N, Yazigi N, Vissuzaine $\mathrm{C}$, et al. Polymerase chain reaction assay fo the detection of Helicobacter pylori in gastric biopsy specimens: Comparison with culture, rapid urease test and histopathological tests. Gut 1994;35:905-8.

18 Clayton C, Kleanthous K, Tabaqchali S. Detection and identification of Helicobacter pylori by the polymerase chain reaction. 7 Clin Pathol 1991;44:515-16.

19 Guesdon JL, Ternyn CKT, Avrameas S. The use of avidinbiotin interaction in immunoenzymatic techniques. biotin interaction in immunoenzym

20 Norton AJ, Jordan S, Yeomans P. Brief, high-temperature heat denaturation (pressure cooking): A simple and effective method of antigen retrieval for routinely processed tissues. F Pathol 1994;173:371-9.

21 Diss TC, Pan L, Peng H, Wotherspoon AC, Isaacson PG Sources of DNA for detecting B-cell monoclonality using PCR. F Clin Pathol 1994;47:493-6.

22 Clayton CL, Kleanthous H, Coates P, Morgan D, Tabaqchali S. Sensitive detection of Helicobacter pylori by using polymerase chain reaction. F Clin Microbiol 1992; 30:192-200.

23 Bode G, Mauch F, Malfertheiner P. The coccoid forms of Helicobacter pylori. Criteria for their viability. Epidemiol Infect 1993;111:483-90. 